\title{
COMPARISON BETWEEN DEXAMETHASONE AND COOL JAW WRAP ON POSTOPERATIVE PAIN AFTER SURGICAL REMOVAL OF LOWER WISDOM TEETH
}

\author{
NASMA M. AL-FAHAD*, WAEL SHEET SHALLAWE ${ }^{* *}$ \\ ${ }^{*}$ B. D. S. Ministry of Health, Nineveh Health Department, Mosul, Iraq, ${ }^{* *}$ B. D. S., F. I. B. M. S, Head of the Department of Oral and Maxillofacial \\ Surgery, College of Dentistry, University of Mosul, Mosul, Iraq \\ Email: prateek.jain246@gmail.com \\ Received: 28 Jan 2017, Revised and Accepted: 20 Apr 2017
}

\begin{abstract}
Objective: The aim is to compare between the effect of cool jaw wraps and dexamethasone injection on postoperative pain and evaluate the quality of life after surgical removal of lower wisdom tooth.
\end{abstract}

Methods: Extraction of impacted lower third molar will surgically operate (by the same difficulty of surgical extraction and same operator) on 30 patients, which divide into three groups, each group have 10 patients.

We will instruct the patients in cool jaw wrap group to put cool jaw wrap after the operation. While the second group give dexamethasone injection after the operation. The last group which is the control group will left them with the usual instruction postoperatively.

This study evaluates the facial pain, swelling, and trismus on days 1,2 and 7 postoperatively. Objective measurements of swelling, pain, and trismus were undertaken at days 1, 2 and 7. The quality of life questionnaire was estimated at day 7 postoperatively.

Results: Cool jaw wrap showed no significant differences on the postoperative pain when it used after surgical removal of the lower third molar BUT have significant differences on the Quality of life of patients.

Conclusion: Cool jaw face wrap can be recommended as a safe method that participates in some degree to reduce postoperative pain, it easy to handle, comfort, avoiding damage by freezing due to the barrier between cool jaw and skin and the patient can avoid the side effect of dexamethasone and the phobia from the injection.

Keywords: Words, Pain, Cold therapy, Impacted tooth

(C) 2017 The Authors. Published by Innovare Academic Sciences Pvt Ltd. This is an open access article under the CC BY license (http://creativecommons.org/licenses/by/4.0/) DOI: http://dx.doi.org/10.22159/ijcpr.2017v9i4.20754

\section{INTRODUCTION}

A wisdom tooth refers to one of the molars in humans. Wisdom teeth generally appear between the ages of 17 and 25 [1].

The removal of the impacted mandibular third molar is a common oral surgical procedure and it is often joined by complications, which are distressing to patients [2]. Pain, trismus and swelling are common problems reported by Ogini FO [3], and they are thought to arise from inflammatory response which is a direct and immediate consequence of the surgical procedure [4]. Many clinicians have thus highlighted the necessity for better pain control in patients who undergo third molar surgery [5]. Several methods of controlling the immediate inflammatory response associated with the third molar surgery. These include different surgical closure techniques with or without incorporation of drains [6]. Use of drugs such as non-steroidal antiinflammatory drugs (NSAIDs), paracetamol, corticosteroids [7-8]. Antibiotics [9]. Other reported modalities include physical therapeutic methods such as cryotherapy [10] and laser application [11].

In the early nineties, Cool Jaw partnered with leading oral and maxillofacial surgeons to develop a new generation of hot and cold therapy. Cool Jaw product line utilizes a unique, patented pocket design that allows patients to easily replace gel packs without compromising compression.

Cool Jaw's exclusive design helps promote patient compliance by allowing them to fulfil their post-operative care instructions in an easy, non-evasive manner. Cool Jaw strives to continually innovate, which is why especially excited to add heat therapy to this product offering.

Both chronic pain, (like teeth grinding or clicking of the jaw, and pain following a surgical procedure can benefit from Cool Jaw Wrap for the jaw treatment. Grinding the teeth causes permanent tooth damage as well as sore muscles which may lead to TMJ issues. Cold therapy offers immediate relief.

Cool Jaw wraps are ideal for wisdom teeth extractions, reconstructive jaw surgery, implant surgery, maxillary and mandibular trauma, and genioplasty, as well as facelifts and TMJ pain [12].

The aim is to compare between the effect of cool jaw wraps and dexamethasone injection on postoperative pain and evaluate the quality of life after surgical removal of lower wisdom tooth.

\section{MATERIALS AND METODES}

\section{Patients and sampling design}

In this prospective clinical comparative study thirty patients have impacted lower wisdom teeth who attended to specialized dental center (dept. of oral and maxillofacial surgery/Erbil/Iraq) from august 2016 to October 2016, the impacted lower wisdom teeth are surgical extracted from the patient.

The patients were assigned randomly into a control group and two study groups each group consisted of 10 patients.

\section{Methods}

Postoperative pain was evaluated using a visual analogue scale (VAS) [13] $10 \mathrm{~cm}$ in length, ranging from 0 "no pain" to 10 "the worst possible pain". Patients were also instructed to report the number of rescue analgesic tablets required on the day of surgery (till $24 \mathrm{~h}$ postoperatively) and what is the time of the first analgesic tab was taken.

Results

A total of 30 patients were included in this statistic study who completed the questionnaire and measurements. These patients 
randomly divided into three groups. There were no missing data and all patients included in the study attended all the follow-up visits. The time of operations ranged between 20 to $30 \mathrm{~min}$. The mean age of patients was 22.5 in cool jaw wrap group, 22.4 in dexamethasone group and 21.1 in control group. According to Kruskal-Wallis test, pain measurements between groups before and after surgery showed that there were is no significant difference between the three groups that $\mathrm{P}$ value $=0.953$ at the first day before operations (VAS 1 ), $P$ value $=0.324$ at second day after operation(VAS 2 ) and $P$ value $=0.440$ at seventh day after operations (VAS 7). P value>0.05 (table 1).

Table 1: Comparison between vas 1, vas 2 and vas 7 in the three groups

\begin{tabular}{llll}
\hline VAS & Groups & P value & duncan \\
\hline sVAS 1 & group1 & 0.953 & $\mathrm{~A}$ \\
& group2 & & $\mathrm{A}$ \\
VAS 2 & group3 & 0.324 & $\mathrm{~A}$ \\
& group1 & & $\mathrm{A}$ \\
VAS 7 & group2 & & $\mathrm{A}$ \\
& group3 & 0.440 & $\mathrm{~A}$ \\
& group1 & & $\mathrm{A}$ \\
$\mathrm{A}$ & & $\mathrm{A}$ \\
\hline
\end{tabular}

\section{DISCUSSION}

In this study, the Kruskal-Wallis Test for pain showed that there were is no significant difference between the three groups. As shown in table 1 .

Hubbard and Denegar [14] concluded that cryotherapy is effective in reducing pain. However, several of the studies they reviewed were confounded by the concomitant use of compression, requiring - at a minimum - the patient's active participation in the treatment [15].

The literature review on cryotherapy after intraoral surgical procedures by Greenstein [16] was inconclusive with respect to the clinical benefits of cryotherapy including pain outcomes.

Our subjects were instructed to use their passively applied thermal wraps continuously for $24 \mathrm{~h}$ or through the morning the day after surgery. The thermal wraps took approximately 40 min to freeze initially and then stayed cold for about 20 to $25 \mathrm{~min}$.

The application, then, was intermittent because the thermal wrap had to be refrozen before reapplication. However, once applied, the device was passive; a subject's hands were free, a distinct difference from methods of cryotherapy requiring a patient to actively hold the device in place, potentially reducing compliance with treatment including the total time the cryotherapy was applied.

\section{CONCLUSION}

Cool jaw face wrap showed no significant reduction of pain after surgical removal of lower third molar however it can be recommended as a safe method in reducing postoperative pain to some degree, it easy to handle, comfort, avoiding damage by freezing due to the barrier between cool jaw and skin.

\section{CONFLICT OF INTERESTS}

\section{Declare none}

\section{REFERENCES}

1. Divya T. Microwave-assisted development and statistical optimization of the porous tablet by vaporization technique. J Pharm Sci Res 2014;6:363-7.

2. Saheeb BD, Obuekwe ON. An audit of mandibular third molar surgery. Nig J Surg Res 2001;3:66-74.

3. Ogini FO, Ugboko VI, Assam E, Ogunbodede EO. Postoperative complaints following impacted mandibular third molar surgery in Ile-Ife, Nigeria. South Afr Dent J 2002;57:264-8.
4. McGrath C, Comfort MB, Lo EC, Luo Y. Changes in quality of life following third molar surgery-the immediate postoperative period. Br Dent I 2003;194:265-8.

5. Bamgbose BO, Akinwande JA, Adeyemo WL, Ladeinde $\mathrm{AL}$ Arotiba GT, et al. Effects of co-administered dexamethasone and diclofenac potassium on pain, swelling and trismus following third molar surgery. Head Face Med 2005;1:11:1-11.

6. Ordulu M, Aktas I, Yalcin S. Comparative study of tube drainage versus methylprednisolone after third molar surgery. Oral Surg Oral Med Oral Pathol Oralradiol Endod 2006;101:96-100.

7. Bonnefont J, Courade JP, Alloui A, Eschalier A. Antinociceptive mechanism of action of paracetamol. Drugs 2003;63:1-4.

8. Chopra D, Rehan HS, Mehra P, Kakkar AK. A randomised double-blind, placebo-controlled study comparing the efficacy and safety of paracetamol, serratiopeptidase, ibuprofen and betamethasone using the dental impaction pain model. Int J Oral Maxillofac Surg 2009;38:3505.

9. Salmerón-Escobar JI, del Amo-Fernández de Velasco A. Antibiotic prophylaxis in oral and maxillofacial surgery. Med Oral Patol Oral Cir Bucal 2006;11:E292-6.

10. Sortino F, Messina G, Pulvirenti G. Evaluation of postoperative mucosa and skin temperature after surgery of impacted third molars. Minerva Stomatol 2003;52:393-9.

11. Markovoric A, Todovoric LJ. Effectiveness of dexamethasone and low-power laser in minimizing oedema after third molar surgery: a clinical trial. Int J Oral Maxillofac Surg 2007;36:226-9.

12. www.cooljaw.com; 2012. [Last accessed on 20 Dec 2017]

13. Grossi GB, MD Maiorana C, Garramone RA, Borgonovo A, Creminelli L, Santoro F. Assessing postoperative discomfort after third molar surgery: a prospective study. J Oral Maxillofac Surg 2007b;65:901-17.

14. Hubbard TJ, Denegar CR. Does cryotherapy improve outcomes with soft tissue injury? J Athl Train 2004;39:278.

15. Forouzanfar T, Sabelis A, Ausems S. Effect of ice compression on pain after mandibular third molar surgery: a single-blind, randomized controlled trial. Int J Oral Maxillofac Surg 2008;37:824.

16. Greenstein G. Therapeutic efficacy of cold therapy after intraoral surgical procedures: a literature review. J Periodontol 2007;78:790Y-800.

\section{How to cite this article}

- $\quad$ Nasma M AL-Fahad, Wael Sheet Shallawe. Comparison between dexamethasone and cool jaw wrap on postoperative pain after surgical removal of lower wisdom teeth. Int J Curr Pharm Res 2017;9(4):33-34. 